Témoigner Témoigner. Entre histoire et mémoire

Getuigen Revue pluridisciplinaire de la Fondation Auschwitz

127 | 2018

Perpétuation de la violence après 1918

\title{
Noord-Italië: in de sporen van het verzet tegen het fascisme. Drie gedenktekens voor de slachtoffers
}

En Italie du nord, sur les traces de la résistance au fascisme. Trois mémoriaux en souvenir des victimes

\section{Yannik van Praag}

Traducteur : Rita Roggen

\section{(2) OpenEdition}

1 Journals

Édition électronique

URL : https://journals.openedition.org/temoigner/7853

DOI : $10.4000 /$ temoigner.7853

ISSN : 2506-6390

Éditeur :

Éditions du Centre d'études et de documentation Mémoire d'Auschwitz, Éditions Kimé

Édition imprimée

Date de publication : 1 octobre 2018

Pagination : 106-112

ISBN : 978-2-930953-076

ISSN : 2031-4183

Référence électronique

Yannik van Praag, «Noord-Italië: in de sporen van het verzet tegen het fascisme. Drie gedenktekens voor de slachtoffers», Témoigner. Entre histoire et mémoire [Online], 127| 2018, Online op 10 février 2022, geraadpleegd op 14 février 2022. URL: http://journals.openedition.org/temoigner/7853 ; DOI: https://doi.org/10.4000/temoigner.7853 


\section{Herinneringsplek}

\section{NOORD-ITALIË: IN DE SPOREN \\ VAN HET VERZET TEGEN HET FASCISME. DRIE GEDENKTEKENS VOOR DE SLACHTOFFERS.}

De vzw Ami, entends-tu ? en de ANPI (Nationale vereniging van de Italiaanse partizanen) hebben eind september 2017 een studiereis naar NoordItalië georganiseerd in de sporen van het verzet tegen het fascisme. Het voornaamste doel van deze ontdekkingstocht was om ter plaatse een reis voor groepen jongeren en jongvolwassenen te evalueren en af te werken. De reis



haar medewerking verleend.

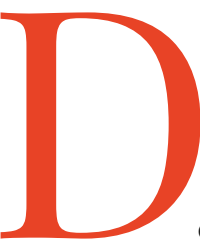

e groep bezocht verschillonde gedenklatsen van Mllaan tarzabotto, om dag na dag meer Marzabotto, on dag ha dag meer te Verzet tegen de Italiadenis van het Soms geber de dal Som geben uit die tijd. Het not directe getuigen uit die tijd. Het noorden van van da vertont de van dat vertoden, omdat het de willeSocion Sociale Republiek (RS) tot aan diens den marvermoedelijkde somberste brutaalste van het Italiaanse fascisme.
$\mathrm{Na}$ het succes van de geallieerden Sicilië in de zomer van 1943 verliest Mussoliniop 24 julirat3 zinn verlest Anderenders wordth en krijethij huist in Camo Inperate Op 8 septer p 8 septuber wordt de Italianse wordt Mu puliek gemaakt en de $12^{\circ}$ wordt Mussolini teruggetrokken doo hoofd te conman hoofd te staan van een regering die de chent militair contingent. heid ann
De feitelijke beslissingen worden niet genomen door Mussolini en zijn

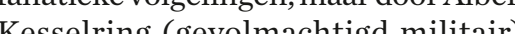
Kesselning (gevolmachtigd miltair), (iijk lijk genach RSI Duitse divisies die Italie ovevolen' Duitse divisies die It

Van meet af an wordt het regime decon in het hele lat Het behoudt den in het hele la controleover de stadskernenende vlaktijk nar ne je berzetsgroepen hun. Darbereiden de verzetsgrom hilide. Het Verzet zou zowat 250000 strijders  len. Daarbij komen nog tienduizenden n in de steden en op het plattelannet in de stedene op het plater

hiervan een gevolg. De Duitsers en de fascistische milities treden hardhandig op tegen de gewapende verzetslieden en ok tegen al wie hen onderdak verleent of te eten geeft.

Wij stellen hier drie gedenktekens or die werden opgericht ter ere van de slachtoffers van dit geweld. Ze verdjzen naris ver wer vorwij. Veel meer dan de verzetsdaden het Italï va nar een bugeroorlog die gang in vuur en vlam heeft gezet.

\section{HET BLOEDBAD VAN LA}

BENEDICTA

In het natuurpark van Capanne di ten noordenvan Genua, in de Apennijnen, aan de grens van Piëmont n Ligurië, rijzen de ruïnes op van de benedictijnerabdij. De ve

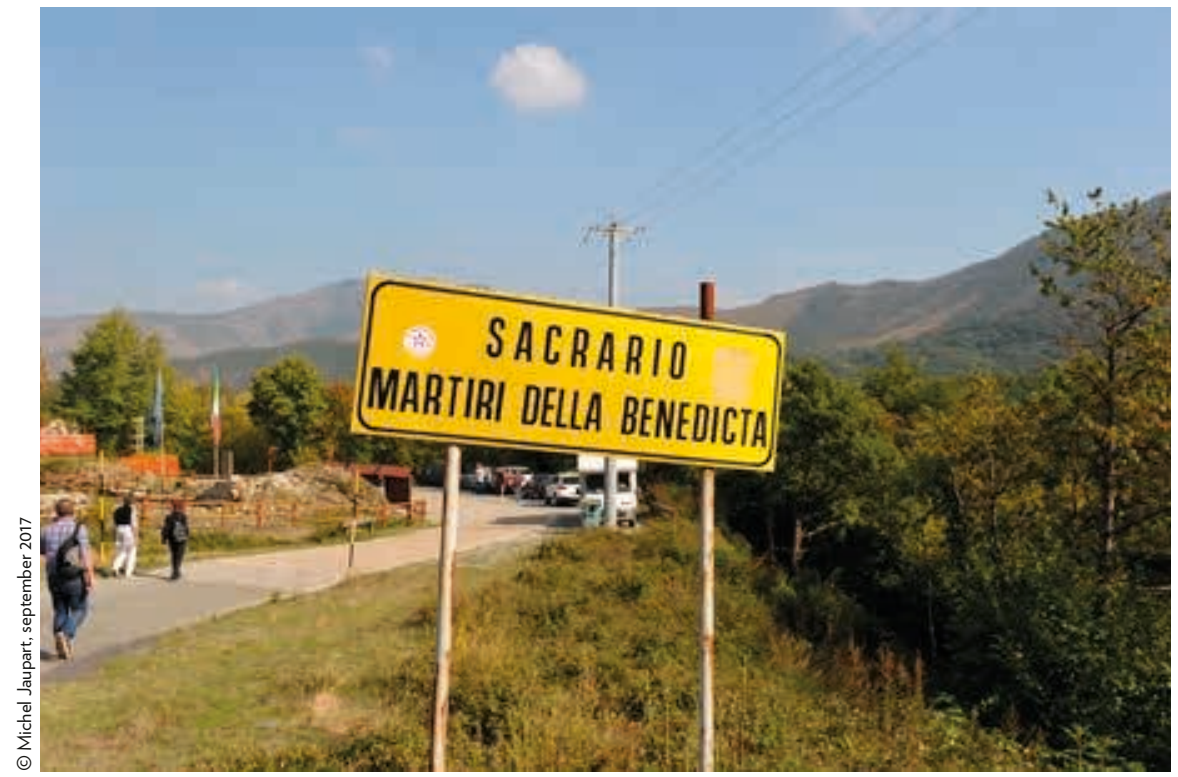




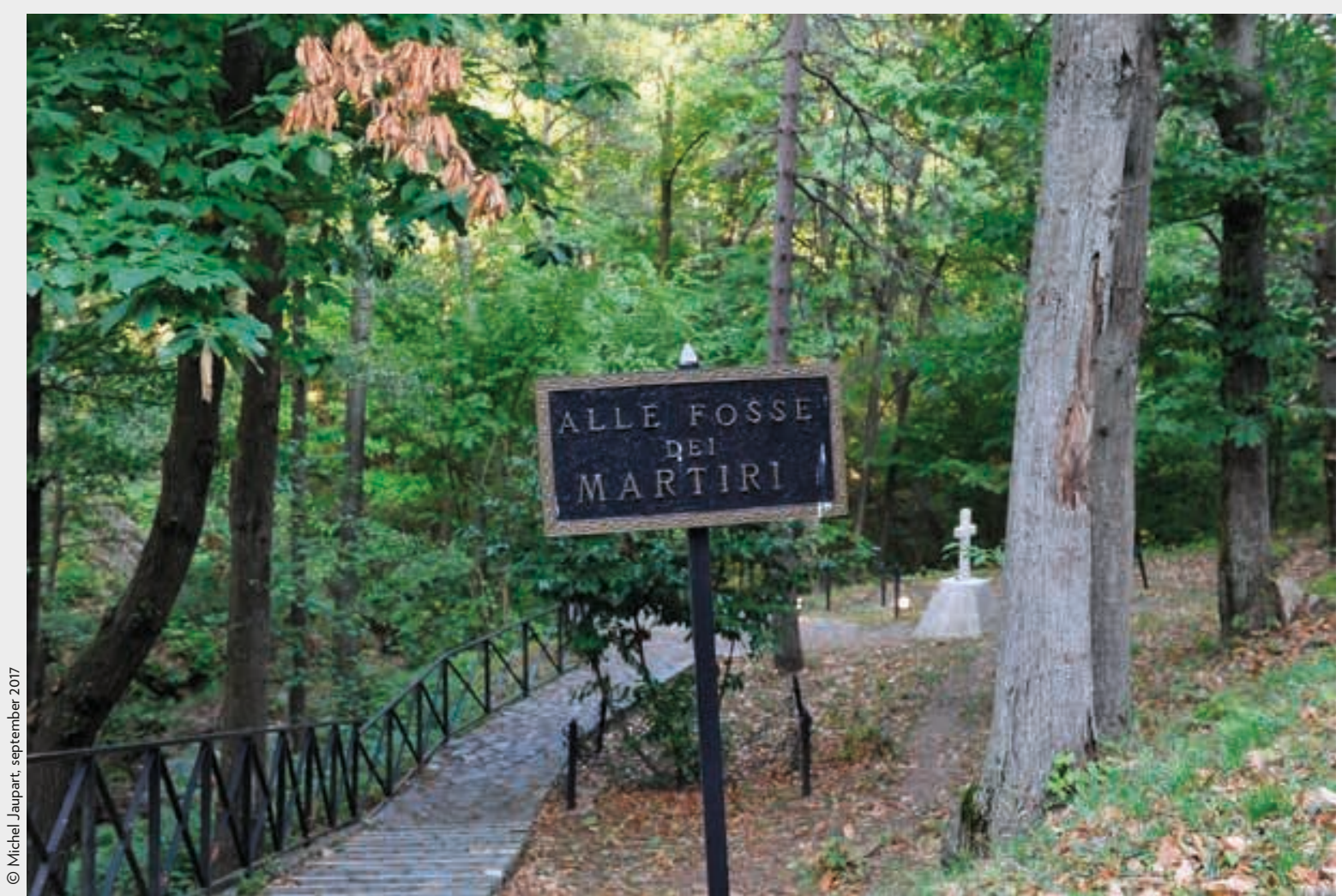

Pad naar

het graf van de

van La Benedicta.

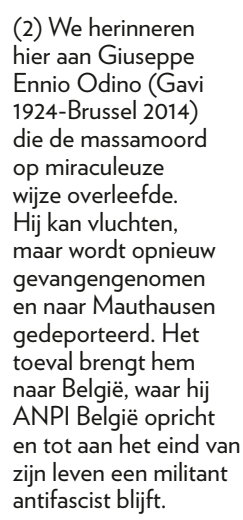

• die abdij waren in april 1944 het tonee van de grootste massamoord op partiWereldoorlog.

Sinds de uitroeping van de RS vluchten dienstweigeraars en jonge mensen uit de streek, die weigeren om de wapens op te nemen onder die ang, har de hep tels. De groep groeit gestaag en in de lente van 1944 zijn Tussen 6 en.

Tussen 6 en 11 april 1944 blokkere 2500 soldaten van de $356^{\circ}$ divisie van de en en starten het offensief tegen de par- hebben om zich terug te trekken. De klopjacht duurt verscheidene dagen. De partizanen worden afgeslacht tijdens de gevechten of in koelen bloede afgemaakt als ze worden gevangengenomen. De aanvallers steken de boerderijen in de omgeving in brand en brengen de abdij tot ontploffing. Bijna 150 partizanen worden ter plaatse gefuword tijden opgepakt, andere sneuvelen tijdens de gevechten. Ongeveer 400 partizanen worden gevangengenomen thausen Zowat de helft

Aan het eind van de oorlog blijft de abdij een verlaten ruïne. De plaatse- lijke bevolking houdt de herinneringen aan de slachtoffers levendig, onder andere door herinneringswerk in de scholen.

Thans rijzen er, als eerbetoon aan de vermoorde partizanen, op een tiental meter van de ruïnes van de abdij stenen platen boven de kuilen waarin hun lichamen op een hoop werden gegooid. Het geheel vormt een grote gedenkplaats. Naast de abdij word een gebouw opgericht. Daar komt een documentatiecentrum om alle documenten en archieven met betrekking ver hetogenblik zijn die overa seren.

nze Italiaanse gastheren hebben ons over de gebeurtenissen verteld e onderstrepen dat het belangrijk is dat chet teld wat het fascisie is en hoe noedig cerzethe wen verzethebbengenteer. Zew zen vijf geknevelde gevangenen metmachije negewern werden vermoord en in een massagrafwerden gegooid. Geen enkele Italis in de gevangenis gezeten.

\section{LA CASA CERVI}

Op 25 november 1943 worden Alcide Cervi en zijn zeven zonen - Gelindo Cervi en zijn zeven zonen - Gelindo Aldo (1909), Ferdinanto (1911), Agostino (1916), Ovidio (1918), Et1) (1921) tho (1916), Ovidio (1918), Ettore (1921) - en een van hun kameraden, Quarto in de boerderij van de fengenomen

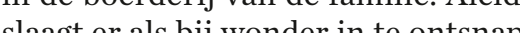
slane pen, maar zijn zonen en hun kameraed

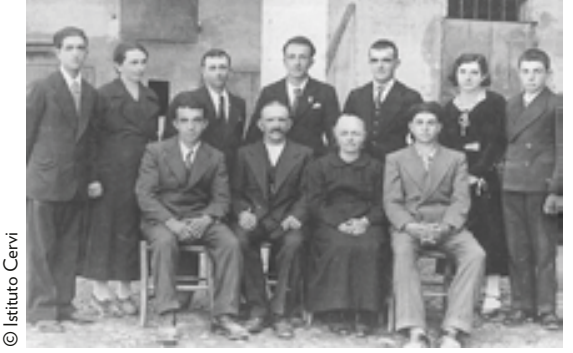

op het schietterrein van Reggio Emilia (tussen Parma en Modena).

De Casa Cervi is nu een museum, symbolische plek als aandenken

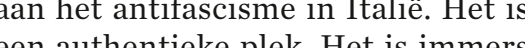
en ar de boerderij waar de famille Cervi in , bouwdom gen tussen de gemeenten Gattatico en trekt de a ha drave lijk is Meten al ind het zo gruwejezoke liefoto van de eenvoudige bo de familie, wavan de eenvoudige boerenfaniwerden afger werden afgenaakt zonder enige vorm Dit is

Dit is geen verhaal van heldhaftig Det van gewapende, georganiseerde partizanen met een stevige ideologische basis. De fanillie Cervi was bescheiden, het waren katholieke plattelandsmenen. Ze is niet bepaald politiek geêngaen de bohalve dantide, de intellectueel en de communistische militant. Later zal zijn vader zegen: 'Aldo heeft me het kleine beetje politiek verstand gegeven waarover ik beschik. Het engagement verdrijuing van Mussolini in juli 1943. Het volk overromplt dan juli 1943 Het volk overrompelt dan de publieke pleinen, de Cervi en andere families $\diamond$ De familie Cervi voór de dramatische gebeurtenissen. 
. brengen rijkelijke pastagerechten naar Campegine en delen ze gratis uit. ${ }^{3}$

Jammer genoeg is de feeststemming van korte duur. De zonen Cervi kieze voor de maquis, maar als de winter kom hebben ze geen middelen van bestaan verleite zomen wilcht on weer naar de valle lijke bo werij wort in de as gelegd.

Het decor van het museum legt een intelligente verbinding tussen het antifascistische verzet en de geschiedenis van het landelijke Italie en de moder repring. De boerderij is inderdaad representatief voor nieuwe ervaringen en de coopperatieve werkvadeling Vate cominat van de eerste trotse bezit

Na de oorlog ontstaat er een ware legendevorming rond het verhaal va deze famille. De moeder heeft het verlies van haar kinderen niet lang overleefi, mar de vader heet zich met al zijn krachten in de strijd tegen het fascisme geworpen. Binnen de PCI verpersoonijht hijhet Italiaanse euroIn de kringen

kringen van intellectuelen die een belangrijke rol hebben gespeeld bij deze herdenking, moeten we de schrijderis van Alciteren, die de geschieUnitò van Alcile Cervi schilderde in Unità, expublicatieutd scember 1953 dan de ingang van het museum worden de bezoekers meteen geconfronteer Het Institut Alcide Cervi, dot Het Institut Alcide Cervi, dat het hus a theekende archieven van Emilio Seren (schrijver, verzetsstrijder, landbouw- vindt er uitgebreide collecties, voora met beterekking tot de geschiedenis van boerenbeweging, de landbouw en het Verzet.Het Instituut coordineert ook de pengog mili vande fanilie Cervi. Ondertussen is dit een park voor agrarisch natuurbeheer gewon, ondenaturilikegrondstoren van de strek en de regre tussen in de kijker te plaatsen.

MONTE SOLE, HET ITALIAANSE ORADOUR

De itse troepen September 1944. De Duitse troepen worden drenter hrongen to aan de Gotenstellunglangsheen de Apenijnen. Daar worden ze ook geconfronteerd met de acties van Simon beveelt So n 'zuive funter Max sicher rond het massief and 'monte Sole, ten zuiden van Bologna, het ankerpunt van de brigade Stella Rossa, bestaande uit strijders met een uiteenlopende poliDe anval start op 29 septe

De aanval start op 29 septembe dor een uisto dorpen Marziotto, e SS Pano en Grizdier Division. De

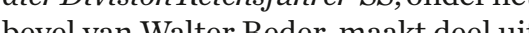
vevel van Walter Reder, haakt deel uit Hij gal o nillo Hij had al de naammeedogenloos te zijn Warschau in de lente van het getto van Warschau in de lente van 1943 en de massano de devolking (Tosen i Sant'Anna di Stazzema

De 'operatie' duurt tot 5 oktober en beperkt zich niet tot de jacht op de partizanen. Devoornaamste slachtoffers zijn binnen het gebied. Somangen zitten binnen het gebied. Sommige dorpen

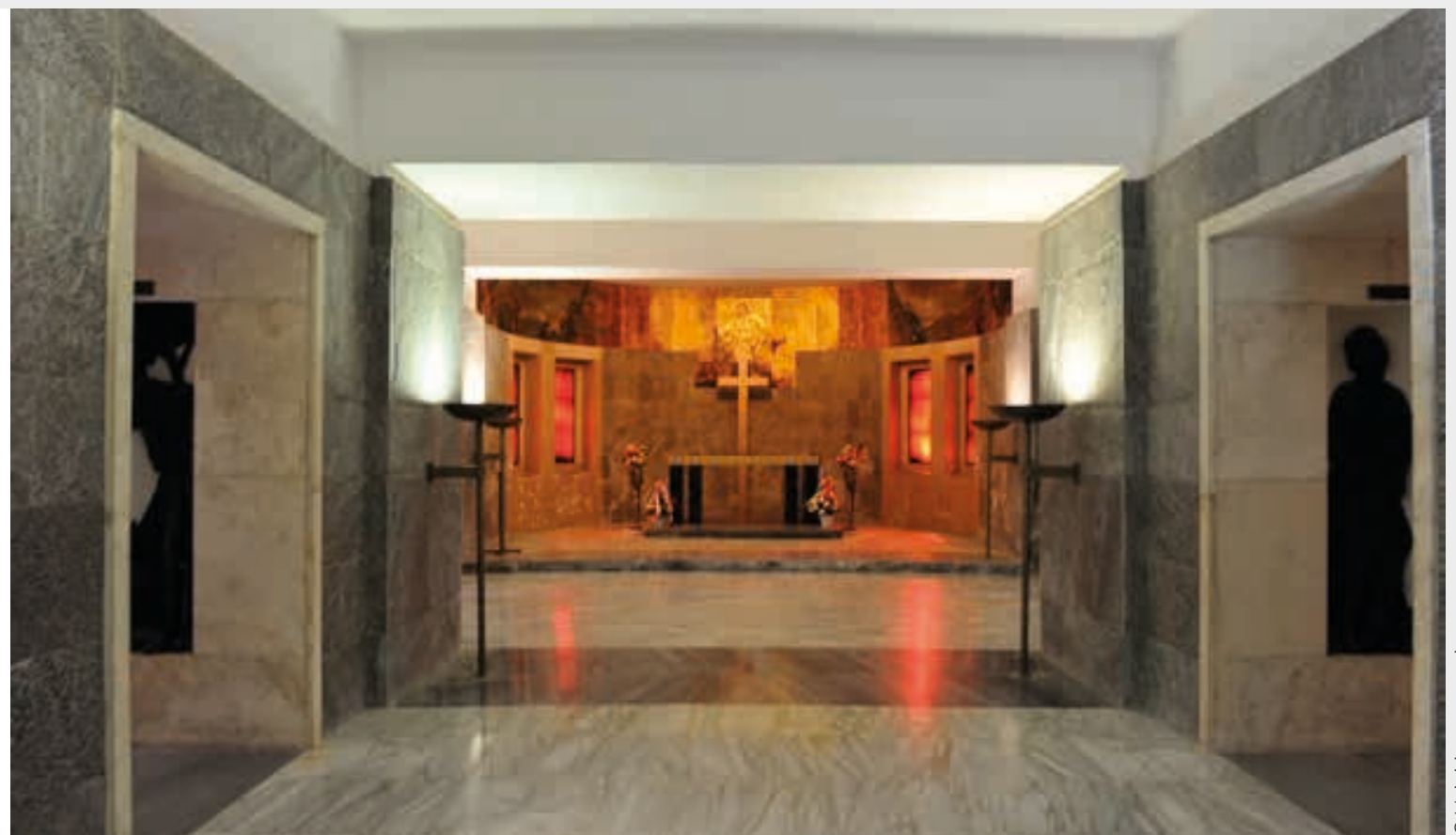

de bewoners systematisch afgeslacht. Het geweld is ongezien. Denken we maar an de moord op honderden burgers (voun, het kerkhof an San Martinoen Casaglia We gaanonshiernietuitsprekenover het exacte antal, nas veel. Het was de grootste massamoord op burgets

Op de plaatsen van de misdaden werden er in het regionale park van Monte Sole gedenkstenen en monumenten geplaatst. Het stadje MarzaCittà messagera di pace (bode van de Citta messaggra di pace (bode van de teken is een eetrot lood is 1 in

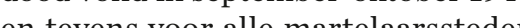
en tevens voor alle martelaarsstede
BESLUIT

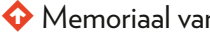

De drie beschreven gedenktekens setuigen van de wreedheden onder de woordigen maar een miniem deel van de geweldgolf die Italië overspoelde tussen 1943 en 1945, van de moordpardij in de Ardeatijnse grotten tot en met (die begint samen met de sichting (die begint samen

De plaats die de geschiedenis van het erzet inneemt in het Italiaanse collectheve geheugen doet ons ook nadenken. De hephnong er op een hel andere manier levendig In Frankrijk werd het verh Fankrijk In Frankijk werd het verhaal letterlijk genstitutionaliseerd, onder andere in eengroot aantal musea. Onwille van de Italië vooral initiatieven van zijhet in repressie tijdens de RSI. Ze vertegen- 


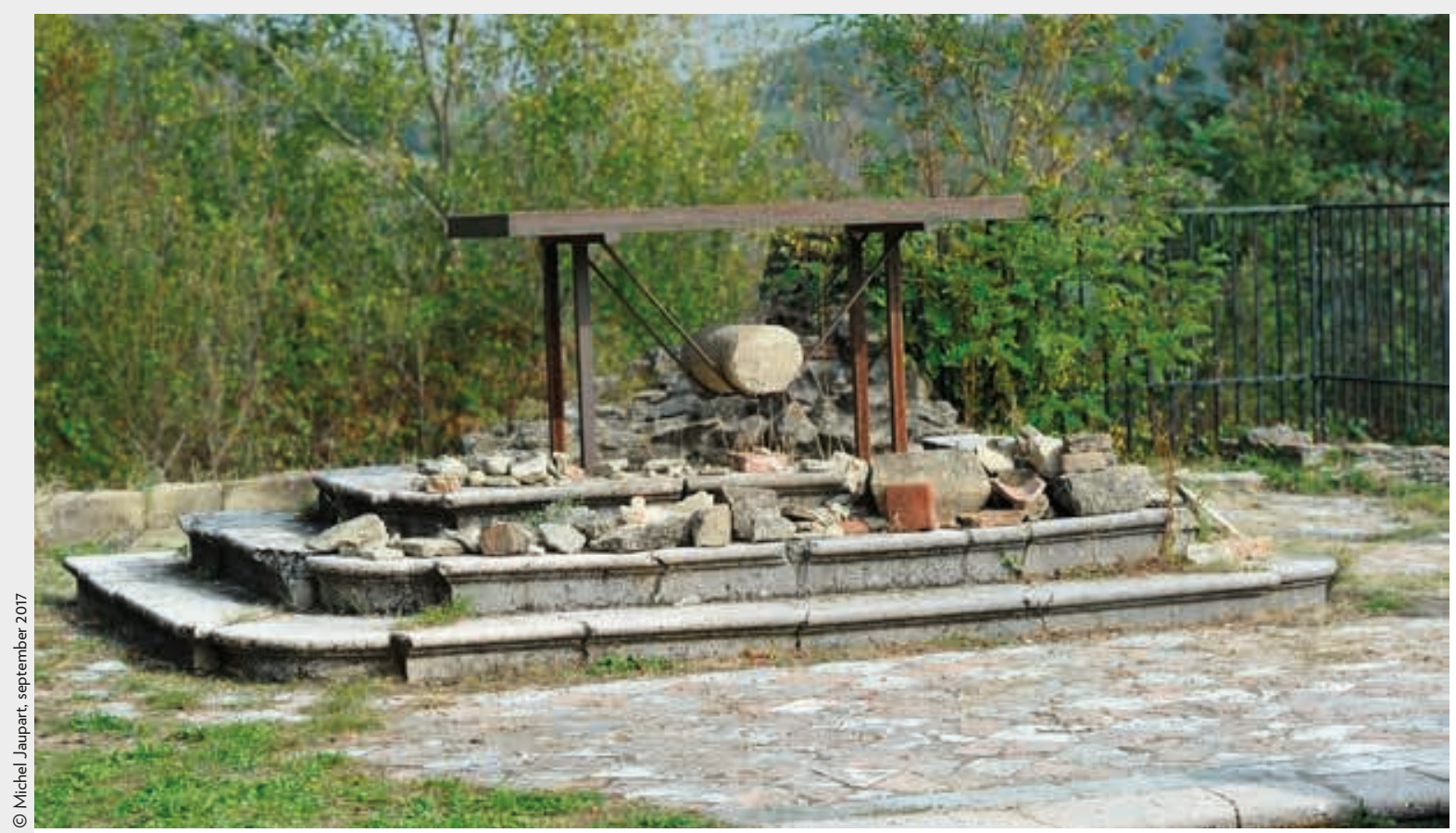

Hart van de kerk, in ruïnes, van San Martino.

(4) Een uitzondering is misschien het Nationaal Museum van de Weerstand in de Van Lintstraat in Anderlecht (http://www. museumresistance.be/).
- sonen en verenigingen, en lokale initiatieven. Perona (1997) schrijft:

Vanaf 1947 werd het land [Italië] bestuurd door een politieke macht, die er geen enkel belang bij had om een erfenis te verheerlijken die werd overgedragen door linkse partijen (vooral de communistische partij en actiepartij). Vanaf dan zaten die immers in de oppositie.

Verenigingen als ANPI, die vandaag 120000 leden telt, spelen een rol als bemiddelaar tussen de generaties. Ze zorgen ervoor dat de getuigenissen een betekenis krijgen en een authentiek sociaal engagement stimuleren bij de jongeren.

In België is er niet zo'n collectief geheugen over het Verzet. ${ }^{4}$ Onze geschiedenis is natuurlijk anders, maar tijdens ons verblijf merkte professor
Anne Morelli op dat in Italië iedereen het verhaal van de broers Cervi kent. Wie kan er, buiten enkele onderzoekers of militanten, een opmerkelijke figuur uit het Belgische Verzet noemen?

Yannik van Praag

(vzw Auschwitz in Gedachtenis) Vertaling uit het Frans: Rita Roggen

\section{$\longrightarrow$ Bibliografie \\ $\Leftrightarrow$ Bernard Droz, 'Préface', in Claudio Pavone, Une guerre civile. Essai historique sur l'éthique de la Résistance italienne, Parijs: Seuil, 2005.}

$\rightarrow$ Ersilia Alessandrone Perona, 'Les musées de la résistance en Italie', in Daniel Grange en Dominique Poulot (red.), L'esprit des lieux. Le patrimoine et la Cité, Grenoble: PUG, 1997, 447-453. 